and the median duration of the disease was 6 years. The indications were rheumatoid arthritis in $63 \%$ (median disease activity score DAS28: 2.4), psoriatic arthritis in 19\% (median DAS28: 2.5 ) and axial spondyloarthritis in $18 \%$ of patients (median BASDAI: 3.0 ). $68 \%$ of patients were new to bDMARD therapy. Previous therapies included conventional synthetic DMARDs $(67 \%$ of patients), steroids (49\%), non-steroidal anti-inflammatory drugs (43\%) and bDMARDs (32\%). Patient satisfaction response rates are shown in table 1.

Abstract AB1468HPR - Table 1. Patient-assessed satisfaction with SB4-pre-filled pen by previous treatment (Full Analysis Set)

\begin{tabular}{|c|c|c|c|c|c|}
\hline & $\begin{array}{l}\text { New to } \\
\text { bDMARD } \\
(n=96)\end{array}$ & $\begin{array}{l}\text { Switch } \\
\text { from } \\
\text { syringe } \\
(\mathrm{n}=22)\end{array}$ & $\begin{array}{c}\text { Switch } \\
\text { from } \\
\text { pen } \\
(n=21)\end{array}$ & $\begin{array}{c}\text { Switch from } \\
\text { intravenous } \\
\text { bDMARD therapy } \\
(n=2)\end{array}$ & $\begin{array}{c}\text { Total }^{*} \\
(n=142)\end{array}$ \\
\hline $\begin{array}{l}\text { General satisfaction: } \\
\text { (very) satisfied }\end{array}$ & 79 (82\%) & 19 (86\%) & $\begin{array}{c}17 \\
(81 \%)\end{array}$ & $2(100 \%)$ & $\begin{array}{c}118 \\
(83 \%)\end{array}$ \\
\hline $\begin{array}{l}\text { Ease of execution: } \\
\text { (very) simple }\end{array}$ & 90 (94\%) & 18 (82\%) & $\begin{array}{c}17 \\
(81 \%)\end{array}$ & $2(100 \%)$ & $\begin{array}{c}128 \\
(90 \%)\end{array}$ \\
\hline $\begin{array}{l}\text { Satisfaction with training } \\
\text { on injection with the } \\
\text { training pen**: } \\
\text { (very) satisfied }\end{array}$ & $\begin{array}{l}81 / 85 \\
(95 \%)\end{array}$ & $\begin{array}{l}20 / 21 \\
(95 \%)\end{array}$ & $\begin{array}{l}16 / 19 \\
(84 \%)\end{array}$ & $2 / 2(100 \%)$ & $\begin{array}{c}120 / 128 \\
(94 \%)\end{array}$ \\
\hline
\end{tabular}

*Missing responses are not included in calculations; total includes one patient with unknown previous therapy.

${ }^{*}$ Number of (very) satisfied patients/total number of patients who received injection training

Conclusions: High level of patient general satisfaction as well as satisfaction with the ease of use were reported with the etanercept biosimilar (SB4) pre-filled pen for patients who were new to bDMARDs or who had switched from other bDMARDs.

Acknowledgements: Biogen $\mathrm{GmbH}$ funded this study. Authors had full editorial control and provided final approval of all content.

Disclosure of Interest: U. Müller-Ladner Consultant for: Biogen, Speakers bureau: Biogen, S. Zinke Consultant for: Biogen, P. Aries Consultant for: Biogen, C. Maucksch Shareholder of: Biogen, Employee of: Biogen

DOI: 10.1136/annrheumdis-2018-eular.1426

\section{AB1469-HPR A STUDY TO INVESTIGATE WHETHER IF ANY BARRIERS IN ETHNIC MINORITY PATIENTS MAY IMPACT ON RESEARCH PARTICIPATION IN A DISTRICT GENERAL HOSPITAL (2011)}

V Ramasamy. Rheumatology, Clinical Research Unit, Barts Health Trust, London, UK

Background: A literature review of the current evidence suggests that research barriers exist within a diverse and ethnic population and that these barriers are often perceived to be cultural, behavioural, structural, organisational or clinical. Though a number of studies have been done showing the impact the above, these cannot be generalised at a local level. Hence, it is of vital importance that those involved in undertaking clinical studies locally are aware of the factors which may be preventing them from recruiting ethnic patients in their respective specialist area. There is a need to evaluate systems currently in place and to investigate whether factors such as attitudes, beliefs, health care professionals approach and patient experience may have an impact on recruitment. Objectives: The aim of this study is to investigate whether any barriers exists within a small sample of ethnic minority patients who have been previously approached to participate in a clinical trial in a local hospital. Methods: A qualitative study involving semi-structured interviews with both consultants active in research and patients with a background of inflammatory conditions invited to participate in a study locally. Purposive sampling was applied in all three groups. Participant information sheets and invitation letters was sent to all participants with a two week follow up by telephone for patients. Consent was taken from all participants, openended questions used during the interviews, the data collected by hand notes and then analysed using the five stages of the framework approach. Data was analysed in 3 groups: ${ }^{1}$ investigators, ${ }^{2}$ consented patients and ${ }^{3}$ unconsented patients.

Results: A total of 24 patients were invited and twelve agreed to attend for individual interviews. Out of twelve investigators approached, eight responded to the invitations. Investigators' displayed positive attitudes towards recruitment, reported language and some cultural barriers along the informed consent pathway and a gap in support systems within research. Patients from both groups reported a lack of awareness in clinical trials. Fears of study drug and a lack of trust to commit were the main themes that emerged from the unconsented group. Cultural barriers did not have an impact on the informed consent process in both groups. Conclusions: This study is among the first that has been conducted in our trust and focused on main areas of qualitative research looking at patients' responses when invited to participate in a trial and complexities of recruitment from a healthcare professional perspective. The findings provide evidence of research barriers that exist within the trust perceived by investigators and patients Unfortunately, few studies have focused on various background of ethnicity within different specialties. This could be because it is difficult to carry out studies without focusing specifically on a certain area of disease or a particular group of patients. These findings can only be generalised to areas of research locally upon further exploration of these barriers, which may have a significant impact on the recruitment of ethnic minority patients.

Disclosure of Interest: None declared

DOI: 10.1136/annrheumdis-2018-eular.6283

\section{AB1470-HPR BELIEFS AND SATISFACTION WITH GOLIMUMAB AS SECOND ANTI TNF-ALPHA OF PATIENTS WITH SPONDYLOARTHRITIS. GO-BEYOND}

$\underline{X}_{\text {Juanola }}{ }^{1}$, C.M. González Fernández ${ }^{2}$, S. García-Carazo ${ }^{3}$, J. RodríguezHereida $^{4}$, J. Bachiller-Corral ${ }^{5}$, M. Martín López ${ }^{6}$, M. Retuerto Guerrero ${ }^{7}$, J. Martín Santos $^{8}$, N. Álvarez-Rivas ${ }^{9}$, C. Egües Dubuc ${ }^{10}$, I. Villa-Blanco ${ }^{11}$, A. Laiz ${ }^{12}$, J. V. Tovar Beltrán ${ }^{13}$, E. Beltrán ${ }^{14}$, E. Raya ${ }^{15}$, R. Ibáñez Bosch ${ }^{16}$, J. Manero ${ }^{17}$, J. Pons Dolset ${ }^{18}$, B. García Magallón ${ }^{19}$, Y. Mestre ${ }^{20}$, S. Fernández ${ }^{20}$,

M. Mosquera ${ }^{20}$, L. Cea-Calvo ${ }^{20}$, J.J. Alegre-Sancho ${ }^{21} .{ }^{1}$ Rheumatology, H. U. Bellvitge, Barcelona; ${ }^{2}$ Rheumatology, H. G. U. Gregorio Marañón; ${ }^{3}$ Rheumatology, H. U. La Paz; ${ }^{4}$ Rheumatology, H. U. de Getafe; ${ }^{5}$ Rheumatology, H. U. Ramón y Cajal; ${ }^{6}$ Rheumatology, Instituto de Investigación H. U. Doce de Octubre, Madrid; ${ }^{7}$ Rheumatology, H. U. de León, León; ${ }^{8}$ Rheumatology, H. U. Río Hortega, Valladolid; ${ }^{9}$ Rheumatology, HU Lucus Augusti, Lugo; ${ }^{10}$ Rheumatology, H. U. Donostia, Donostia; ${ }^{11}$ Rheumatology, H. Sierrallana, Torrelavega; Cantabria; ${ }^{12}$ Rheumatology, H. de la Santa Creu i Sant Pau, Barcelona; ${ }^{13}$ Rheumatology, $H$. General U. de Elche, Elche; ${ }^{14}$ Rheumathology, H del Mar, Barcelona;

${ }^{15}$ Rheumatology, H. U. San Cecilio, Granada; ${ }^{16}$ Rheumatology, Complejo H. de Navarra, Pamplona; ${ }^{17}$ Rheumatology, H. U. Miguel Servet, ${ }^{18}$ Rheumatology, $H$. Royo Villanova, Zaragoza; ${ }^{19}$ Rheumatology, H. San Jorge, Huesca; ${ }^{20}$ Medical Affairs, Merck Sharp and Dohme, Madrid; ${ }^{21}$ Rheumatology, H. U. Doctor Peset, Valencia, Spain

Objectives: In patients with spondyloarthritis (SpA: axial SpA or psoriatic arthritis $[\mathrm{Ps} A]$ ), treated with golimumab as second biological therapy (after failure or withdrawal of a first anti TNF- $\alpha$ drug), we describe patients' insights with regard to their beliefs and their satisfaction with golimumab therapy.

Methods: Patients on golimumab from GO-BEYOND, a retrospective study undergone in 20 Spanish rheumatology clinics, were requested to respond to the Beliefs About Medicines Questionnaire (BMQ). Statements of the $\mathrm{BMQ}$ include a 5-item necessity and a 5-item concern scale with Likert response options from "strongly agree" to "strongly disagree". Patients also responded to questions on their satisfaction and experience with golimumab self-injection. Descriptive data are displayed, and responses to the $\mathrm{BMQ}$ in axial SpA vs PsA patients were compared with the chisquare test.

Results: 123 patients on golimumab as second anti TNF- $\alpha$ responded (81 axial $\mathrm{SpA}$ and $42 \mathrm{PsA}$, mean age 49 years [SD=11], 40\% women). Patients showed strong beliefs in the necessity of golimumab for the treatment of their SpA (percentages of "agree" or "strongly agree" to the necessity statements: $50 \%-80 \%$ ), but also concerns: half the patients agreed/strongly agreed to be worried about long term effects of golimumab, and $\approx 30 \%$ about becoming too dependent on the drug (table 1). Responses were similar in axial SpA and PsA patients (table 1). 111 patients declared to self-inject golimumab. Of these, $22.7 \%$ considered the experience with self-injection as very positive, $66.4 \%$ as positive $10.0 \%$ neutral and only $0.9 \%$ unfavourable, and the use of the device very easy $(37.3 \%)$, easy $(57.3 \%)$, neutral $(3.6 \%)$ and only $1.8 \%$ difficult. Finally $36.4 \%$ and $49.1 \%$ were very satisfied or satisfied with the interval of administration of golimumab, $11.8 \%$ were neutral and only $1.8 \%$ and $0.9 \%$ declared to be dissatisfied or very dissatisfied. 
Abstract AB1470HPR - Table 1. Percentage of patients who responded "strongly agree" or "agree" to the BMQ statements

\begin{tabular}{|c|c|c|c|}
\hline & $\begin{array}{c}\text { All } \\
(n=123)\end{array}$ & $\begin{array}{c}\text { Axial SpA } \\
(n=81)\end{array}$ & $\begin{array}{c}\text { PsA (n= } \\
42)\end{array}$ \\
\hline \multicolumn{4}{|l|}{ Necessity scale } \\
\hline My health, at present, depends on golimumab* & $72.7 \%$ & $71.8 \%$ & $75.0 \%$ \\
\hline My life would be impossible without golimumab* & $51.5 \%$ & $49.3 \%$ & $57.1 \%$ \\
\hline Without golimumab ${ }^{*}$, would be very ill & $63.6 \%$ & $60.6 \%$ & $71.4 \%$ \\
\hline My health, in the future, will depend on golimumab* & $42.4 \%$ & $46.5 \%$ & $32.1 \%$ \\
\hline Golimumab* protects me from becoming worse & $89.7 \%$ & $88.7 \%$ & $85.7 \%$ \\
\hline \multicolumn{4}{|l|}{ Concerns scale } \\
\hline Having to inject golimumab* worries me & $29.3 \%$ & $29.6 \%$ & $28.6 \%$ \\
\hline I sometimes worry about the long-term effects of golimumab* & $49.5 \%$ & $49.3 \%$ & $50.0 \%$ \\
\hline Golimumab* is a mystery to me & $35.7 \%$ & $35.2 \%$ & $37.0 \%$ \\
\hline Golimumab ${ }^{\mathbb{x}}$ disrupts my life & $7.1 \%$ & $9.9 \%$ & $0.0 \%$ \\
\hline I sometimes worry about becoming too dependent on golim & $30.3 \%$ & $32.4 \%$ & $25.0 \%$ \\
\hline
\end{tabular}

All $p$-values $>0.1$. *For a better understanding, the commercial name was used in the patients' questionnaire

Conclusions: Patients with SpA currently using golimumab as second anti TNF-alpha describe strong beliefs in the necessity of golimumab and good experience and satisfaction with self-administration. The $B M Q$ also identified concerns that should be addressed in the clinic. The study is limited to the subset of patients still on golimumab at the study visit. Acknowledgements: Funded by Merck Sharp and Dohme, Spain Disclosure of Interest: None declared DOI: 10.1136/annrheumdis-2018-eular.2683

\section{AB1471-HPR INVESTIGATION OF THE EFFECT OF MANUAL THERAPY AND CERVICAL STABILISATION EXERCISES ON DISABILITY, KINESIOPHOBIA, DEPRESSION AND ANXIETY IN CHRONIC NECK PAIN PATIENTS: A PILOT STUDY}

\section{Y Ozel Aslıyuce, D. Onan, O. Ulger. Health of Sciences, Ankara, Turkey}

Background: Neck pain is a common pain after low back pain and becomes chronic in most of the individuals $(43 \%)$. Due to the severe pain experienced in chronic neck pain (CNP) individuals, the level of disability, depression and anxiety increases and kinesophobia develops. Cervical stabilisation exercises in individuals with CNP are one of the most effective treatment methods applied recently and the main purpose is to provide training of deep cervical muscles. Manual therapy approaches such as suboccipital release and post-isometric relaxation techniques provide relaxation of the fascia and superficial muscles. These techniques are rarely applied compared to cervical stabilisation exercises and the number of studies done in the literature is very limited. The effects of these three approaches in the treatment of pain severity, disability, kinesophobia, depression and anxiety are not known in the patients with CNP.

Objectives: The aim of this study is to investigate the effect of physiotherapy program consisting of suboccipital relaxation technique, post-isometric relaxation technique and cervical stabilisation exercises on pain severity, disability, kinesophobia, depression and anxiety in individuals with CNP.

Methods: Ten patients who have CNP aged 18-65 years (mean age $37.11 \pm 4.26$ ) were included in this study. Pain intensity at rest, activity and night with visual analogue scale (VAS), levels depression with Beck Depression Scale (BDS), anxiety with Beck Anxiety Scale (BAS), kinesiophobia with Tampa Kinesiophobia Scale (TKS) and disability with Neck Disability Index (NDI) were assessed. All participants in the study were included in a 10-session physiotherapy program that included suboccipital relaxation, post-isometric relaxation to the upper part of the trapezius muscle, and cervical stabilisation exercises.

Results: It was found that pain intensity at rest, activity and night were significantly decreased after treatment $(p=0.008)$. Disability $(p=0.008)$ and kinesophobia $(p=0.01)$ level were also significantly dropted. Depression $(p=0.015)$ and anxiety levels $(p=0.024)$ were statistically significantly improved after treatment.

Conclusions: As a result of our study, pain, depression and anxiety levels decreased, kinesophobia and disability were improved after physiotherapy applied to individuals with CNP. The suboccipital relaxation and postisometric relaxation techniques applied before cervical stabilisation exercises increased the adaptation to the exercise by providing relaxation of the painful and tense region in the patients. We think that the activation of the deep cervical muscles is facilitated when the tension of the superficial muscles and the fascia are relaxed. Soft tissue loosening does not result in pain during and-exercise, which may have reduced the tendency for kinesophobia, anxiety and depression in patients.

\section{REFERENCES:}

[1] Gelecek, N. and H. Akkan, The effect of stabilization exercise training on pain and functional status in patients with cervical radiculopathy. J Back Musculoskelet Rehabil, 2017.

[2] Strunk, R.G. and M.A. Hondras, A feasibility study assessing manual therapies to different regions of the spine for patients with subacute or chronic neck pain. J Chiropr Med, 2008. 7(1): p. 1-8.

Disclosure of Interest: None declared DOI: 10.1136/annrheumdis-2018-eular.4667

\section{AB1472-HPR INFLAMMATORY OR RHEUMATOID ARTHRITIS PATIENTS' PERSPECTIVES ON THE EFFECT OF ARTHRITIS GLOVES ON THEIR HAND PAIN AND FUNCTION (A-GLOVES TRIAL): A QUALITATIVE STUDY}

Y Prior $^{1,2}$, N. Arafin ${ }^{1}$, C. Bartley ${ }^{1}$, A. Hammond ${ }^{1} .{ }^{1}$ Health Sciences, University of Salford, Salford; ${ }^{2}$ Rheumatology, MidCheshire Hospitals NHS Trust, Leighton Hospital, Crewe, UK

Background: Arthritis (compression) gloves are frequently provided to people with inflammatory (IA) or rheumatoid arthritis (RA) in the NHS, to help reduce swelling and alleviate hand pain by providing compression and improving circulation. However evidence for their effectiveness is limited. $^{1}$

Objectives: Nested within a randomised controlled trial (RCT) testing the effectiveness of intervention (compression) gloves with control gloves (fitted at least one size too big) in people with RA and IA, this qualitative study aimed to explore patients' perspectives on the effect of the arthritis gloves on their hand pain and function.

Methods: Once randomised, participants were provided joint protection and hand exercise booklets and fitted with either the intervention or the control glove(s) by a trained occupational therapist. ${ }^{2}$ Both gloves had similar thermal qualities but control gloves did not apply compression. Semistructured interviews were conducted with 10 participants, purposively selected from each group $(n=20)$ following 12 weeks of glove wear. Interviews were audio-recorded, transcribed and analysed by three researchers using thematic analysis with a critical realist perspective.

Results: Participants' perspectives on the effects of the arthritis gloves had three emergent sub-themes. These were ${ }^{1}$ Usage: both groups predominantly used the gloves for activities such as wearing them outdoors to keep hands warm, night-time wear to help with sleep, and doing light domestic activities (e.g. dusting). Gloves were not used for cooking or washing-up or for personal activities of daily living (e.g. toileting, grooming) "What didn't help as such, obviously was with washing etc. and toileting because I had to keep taking them off and putting them back on again"," Symptomatology: while some reported that gloves helped to keep their "hand pain in check" others said that gloves had no effect on their hand pain or that they'd found "it's made them worse". Participants from both groups frequently mentioned the warmth element of the gloves, as a positive attribute to help with their symptoms; ${ }^{3}$ Aesthetics: participants had opposing views on the appearance of the arthritis gloves. Some felt that the intervention gloves "look a bit ugly with the seams outside" or stated that they "would not want to wear that colour" but did not think they were obtrusive. Most noticeably, patients seemed to view the arthritis gloves as ordinary everyday gloves, rather than a medical device "if it was cold I wore them outside".

Conclusions: Trial participants reported experiencing similar effects from wearing either the intervention or control gloves, with varied perspectives on whether or not gloves affected hand pain and/or function. Overall, patients did not reflect on the compressive but rather the thermal qualities of the gloves, as warmth was the main effect perceived.

\section{REFERENCES:}

[1] Hammond, et al. Clin Rehabil 2016 30:213-24

[2] Prior, et al. Rheum 2017(Supp1)

Acknowledgements: This project was funded by the NIHR Research for Patient Benefit Programme (PB-PG-0214-33010). The views expressed are those of the author(s) and not necessarily those of the NHS, the NIHR or the Department of Health.

Disclosure of Interest: None declared

DOI: 10.1136/annrheumdis-2018-eular.5980 